\title{
European Consensus Score For Bone Marrow Fibrosis
}

National Cancer Institute

\section{Source}

National Cancer Institute. European Consensus Score For Bone Marrow Fibrosis. NCI

Thesaurus. Code C154809.

A score based on the European Consensus scale, a grading system for the qualitative and quantitative evaluation of bone marrow fibrosis with a score ranging from zero (normal bone marrow) to three (coarse bundles of collag en fibrosis, usually associated with significant osteosclerosis). (Thiele J, Kvasnicka HM, Facchetti F, Franco V, van der Walt J, Orazi A. European consensus on grading bone marrow fibrosis and assessment of cellularity. Haematologica. 2005 Aug;90(8):1128-32.) 